\title{
Influence of conspecific and predatory stressors and their associated odors on defensive burying and freezing responses
}

\author{
JON L. WILLIAMS and DAVID K. SCOTT \\ Kenyon College, Gambier, Ohio
}

\begin{abstract}
In Experiment 1, male rats were exposed to either aggressive (i.e., alpha) or nonaggressive conspecific colonies and tested $24 \mathrm{~h}$ later, with or without alpha odors, for freezing behavior and burying of a wall prod that had been the source of a brief electric shock. The results indicated that prior defeat experience and the presence of alpha odors alone during testing had no significant effects, but the combination of prior defeat and alpha-odor testing significantly decreased burying and increased freezing behavior. In Experiment 2, we examined the effects of noncontact exposure to a cat, as a predatory stressor, during subsequent prod-shock tests involving the presence or absence of cat odors. Exposure to a cat failed to disrupt later prod burying and did not produce freezing. However, the presence of cat odors during testing significantly reduced the amount of defensive burying, without resulting in an increment in freezing. In Experiment 3, rats were given 1,5 , or 30 inescapable preshocks in the presence of either cat odors or a hedonically neutral citronella odor and were tested $24 \mathrm{~h}$ later for prod burying and freezing with or without these odors. Both the cat and the citronella odors resulted in a significant reduction in burying and an increase in freezing for rats given 5 and 30 preshocks and tested in the presence of these respective conditioned odors. For the groups that were given 5 preshocks, preshock and later testing in the presence of cat odors resulted in significantly less prod burying and more freezing than for rats that were preshocked and tested in the presence of citronella. The findings of these three ethoexperimental studies are discussed in terms of the learned-helplessness the ory, the stress-coping-fear-defense (SCFD) theory, and the concept of selective CS-US associability.
\end{abstract}

Examining the relationships among fear, defense, and other responses has recently involved "ethoexperimental" analysis of behavior (e.g., Blanchard, Blanchard, \& Hori, 1989; Blanchard \& Blanchard, 1987; Williams, $1982,1984,1987,1989$; Williams \& Lierle, 1986). The major objective of this type of research is to observe the influence of motivational and contextual variables on a variety of species-typical behaviors in a seminatural laboratory environment. In contrast to this approach, most of the previous research on stress and coping (e.g., learned-helplessness experiments) has focused on the disruption of artificial and arbitrarily defined laboratory responses (e.g., shuttlebox crossing, barpressing). In addition, the existing research has not attempted to examine the concurrent performance of several species-typical responses during testing.

An example of the use of the ethoexperimental approach is the research on conditioned defensive burying behavior (Pinel \& Treit, 1978, 1981; Williams, 1987). If suitable bedding material is available, a rat will use its forepaws

This research was supported by USPHS Research Grant 1-R01NH43815-01 and endowment funds available to the senior author from the Samuel B. Curmmings, Jr., Professorship in Psychology. The authors wish to thank Arthur Leccese for his insightful and helpful suggestions in the preparation of this manuscript. Correspondence may be addressed to Jon L. Williams, Department of Psychology, Kenyon College, Gambier, OH 43022 . to push movable material against (i.e., bury) a conditioned aversive stimulus, such as a prod that has been paired with a single electric shock. Although many investigators consider this to be an example of a defensive response based on cognitive processes (e.g., Pinel \& Treit, 1978, 1981), others have claimed that it may be a form of nondirected burrowing behavior (e.g., Peacock \& Wong, 1982) or a nest-maintenance response (Fanselow, Sigmundi, \& Williams, 1987) in which the prod stimulus is coincidentally buried. Regardless of the interpretation of the nature and function of this response, numerous investigators have found that the amount of prod burying is a good index of fear and/or anxiety (e.g., Pinel \& Treit, 1981; Treit, 1985). Furthermore, this reliable behavioral phenomenon is unusual in that it represents a combination of learned and unlearned behaviors. That is, rats learn to bury the specific prod associated with a painful stimulus, and yet the topography of the burying response is an unlearned series of rapid forepaw movements.

Recently, Williams (1987) examined the influence of inescapable shock, conspecific stress odors, and shock controllability using the defensive-burying paradigm. Separate groups of rats were given a session of inescapable shocks or no shock, and later were tested for defensive prod burying and freezing in a chamber that contained odors from either stressed (i.e., previously shocked donors) or nonstressed rats. Following the prod shock, 
rats that had experienced prior inescapable shocks or had been tested with the stress odors spent significantly less time burying the prod, made smaller piles of bedding, and engaged in more freezing behavior. The results of this experiment also indicated that the combination of prior shock and stress odors during later testing enhanced these effects (Williams, 1987, Experiment 1).

A follow-up study revealed that a yoked group of shocked rats, in contrast to a wheel-turn escape group and one that was restrained but not shocked, later showed significantly less burying and more freezing during burying tests with stress odors present (Williams, 1987, Experiment 2). These data indicate that conspecific stress odors can mediate different degrees of fear, depending on the controllability/uncontrollability of shock as a stressor. These findings led to the stress-coping-fear-defense (SCFD) theory that has been proposed by Williams (1987). In brief, this theory assumes that, through classical conditioning, contextual stimuli associated with an uncontrollable stressful situation induce a state of fear that activates specific defensive systems and behavioral patterns. These fear-induced changes are furthermore assumed to be responsible for disrupting subsequent learned and unlearned responses (see Williams, 1989, for a review of relevant studies). In addition to supporting the basic assumptions of the SCFD theory, the findings of these ethoexperimental studies, reported by Williams (1987), demonstrate that the defensive burying paradigm is an excellent technique for assessing the degree of fear elicited by prior stressors and putative conditioned fear odors because it offers the possibility of measuring several types of defensive responses concurrently (e.g., burying and freezing).

The defensive burying paradigm was used in the present series of experiments in order to pursue the following three objectives. First, this research focused on the behavioral effects of exposure to natural social and predatory stressors (i.e., a dominant conspecific and a cat, respectively), as opposed to the traditional laboratory stressor of electric shock. Second, an assessment was made of the degree of contextual control that ethologically relevant stimuli (i.e., odors of alpha conspecifics and cats) had on subsequent defensive prod-burying and freezing responses. Third, in order to investigate the relationship between pain and the fear of predation, a study was done to examine the relative ease of fear conditioning using fear-relevant odors (i.e., cat odors) and a hedonically neutral odor (i.e., citronella) as putative conditioned stimuli by pairing them with painful shock.

\section{EXPERIMENT 1}

Shock has been the most typical source of stress used to induce learned helplessness and fear-mediated defensive behaviors. Shock is a good stressor because it can be easily and precisely controlled, and it is capable of eliciting a range of species-typical defensive responses and physiological alterations in the rat by means of classical conditioning (e.g., Bolles \& Fanselow, 1980; Fanselow \& Lester, 1987). In terms of the rat's natural environment, however, shock is not as ethologically relevant as other forms of stress-inducing stimuli, such as the pain and fear associated with being defeated by a dominant, or alpha, male conspecific.

Recently, Williams and Lierle (1988) investigated whether the fear induced by contextual cues associated with a repeated conspecific-defeat experience would produce the same pattern of learned-helplessness symptoms as does exposure to a series of inescapable shocks. After 25 consecutive sessions of daily exposure to aggressive or nonaggressive colonies, rats that had been defeated by aggressive residents were later found to show less open-field exploration and poor escape learning in a shuttlebox. These findings parallel the results of many learnedhelplessness studies showing deficits in exploration and escape learning following inescapable shock (see Maier et al., 1983, and Maier \& Seligman, 1976, for reviews of this literature). Thus, it appears that repeated defeat by a dominant conspecific has behavioral consequences similar to those produced by a series of inescapable shocks. However, because all of the subjects in the study by Williams and Lierle were tested with odors of dominant residents present during the open-field and the shuttlebox tests, it is impossible to discern whether repeated defeat alone, or defeat in combination with later reexposure to the stress context of alpha odors, was responsible for the reported disruptions in behavior.

The specific purpose of the present experiment was to determine whether a single session of defeat by an alpha resident would alter later defensive burying and freezing behaviors of an intruder on the basis of the conspecific odors that were present in the test chamber. A factorial design was used in this study with groups of defeated and nondefeated colony intruders later tested for burying and freezing with the soiled bedding of either an alpha colony or a nonalpha (i.e., nonaggressive) colony added to the bedding of the test chamber. Two predictions were made on the basis of the combination of previous findings concerning stress odors and defensive burying (Williams, 1987) and learned-helplessness effects resulting from repeated conspecific defeat (Williams \& Lierle, 1988). First, it was hypothesized that both prior defeat and the presence of alpha odors during testing would, separately, induce moderate levels of fear and thus decrease prod burying and increase freezing to some degree. Second, and more importantly, it was predicted that an accentuation of these response changes would occur for alphadefeated intruders that were subsequently tested in the presence of alpha odors.

\section{Method}

Subjects. Thirty-two male albino rats, weighing 510-590 g at the start of the experiment, were used as subjects. In addition, four colonies of 2- to 3-year-old male rats were used for resident-in- 
truder testing. Each colony consisted of 2 male rats and 1 female rat of a younger age. The results of previous resident-intruder tests indicated that the dominant male rat in two of these colonies was found to be very aggressive, whereas the males in the remaining two colonies were found to be completely nonaggressive during these tests.

Apparatus. The four colonies were each housed in $50 \times 40 \times$ $20 \mathrm{~cm}$ polypropylene tubs with stainless steel wire tops. The floors of the colonies were covered with ground corn-cob bedding material. The four test chambers used for defensive burying were metal 36 $\times 36 \times 41 \mathrm{~cm}$ boxes with openings at the top that were fitted with Plexiglas lids. The bottom of each box was covered with an $8-\mathrm{cm}$ layer of corn-cob bedding material. On one side of the box, $2 \mathrm{~cm}$ above the bedding material, was a wooden dowel that protruded $6 \mathrm{~cm}$ from the wall. The dowel was $15 \mathrm{~mm}$ in diameter and was wrapped with two uninsulated copper wires. Shock presentations through the prod were controlled manually and were administered from a Lafayette 82400 shock source. A white-noise generator was used to produce a background sound that was sufficient to attenuate potentially distracting noises. During testing, a Panasonic V 3200 video camera was mounted above the chamber so that behavior of the subjects could be monitored on an RCA monitor located in an adjacent room.

Procedure. All 32 rats were initially habituated to the test chamber (i.e., metal box) using the following procedure. On Days 1 and 2 , they were placed in preassigned chambers in pairs, and on Days 3 and 4, they were individually placed into the same chambers. Each habituation session lasted $30-35 \mathrm{~min}$.

On Day 5, half of the rats were randomly assigned to be intruders in an aggressive colony and the other half were to be intruders in a nonaggressive colony. Before the resident-intruder session, the colony females were removed, and the intruders were marked on their backs with a colored marker for the purpose of easy identification. The subjects were individually tested as intruders in their assigned aggressive or nonaggressive colonies for a period of $15 \mathrm{~min}$. After each resident-intruder session, samples of alpha odors and nonalpha odors were obtained from the bedding of the aggressive and nonaggressive colonies, respectively.

On Day 6 , the rats were individually placed in the prod-burying chamber with soiled bedding from either alpha or nonalpha rats evenly distributed throughout the bedding on the floor of the test chamber. Then the Plexiglas lid to the chamber was closed, the video camera was positioned above the chamber, and the experimenter went into the adjoining room to observe the subject on the monitor. Upon their initial contact with the prod, the subjects were manually given a very brief (i.e., less than $100 \mathrm{msec}$ ) 6.5 $\mathrm{mA}$ shock. Each rat's behavioral reaction to the shock was scored according to the 5-point scale devised by Gray, Terlecki, Treit, and Pinel (1981). The categories, from 0 to 4, respectively, were: no discernible reaction, startle but no immediate withdrawal, startle and withdrawal to the far end of the chamber, jumping followed by rapid withdrawal, and a reflexive leap to the far end of the chamber. Following the prod shock, the rats were observed for a period of $18 \mathrm{~min}$, and their cumulative burying and freezing times were recorded. Freezing was scored if the rat assumed a low crouching position and ceased all movement, except for vibrissae and nose twitching. Both the total duration and the location of freezing were recorded throughout the session. If the rat buried the prod, the height of the highest pile of bedding within $5 \mathrm{~cm}$ of the prod was measured and recorded. The responses of the rats during prod-shock conditioning and later testing were recorded by an experienced observer using a chart recorder. Previous videotaped observations had been conducted to ascertain that the interreliability of scoring for all of these measures exceeded .95 .

The actual running schedule was arranged so that 8 rats were tested on a single day. Thus, a factorial design was used that consisted of the following four groups of subjects: defeated and tested with alpha odors (D/AO), defeated and tested with nonalpha odors (D/NAO), not defeated and tested with alpha odors (ND/AO), and not defeated and tested with nonalpha odors (ND/NAO).

\section{Results and Discussion}

The mean latencies for each group of subjects to touch the prod and receive a single electric shock were as follows: $15.82 \mathrm{sec}$ for Group ND/NAO, $16.96 \mathrm{sec}$ for Group D/NAO, $18.51 \mathrm{sec}$ for Group ND/AO, and $20.47 \mathrm{sec}$ for Group D/AO. The results of a two-way analysis of variance (ANOVA) revealed that neither the
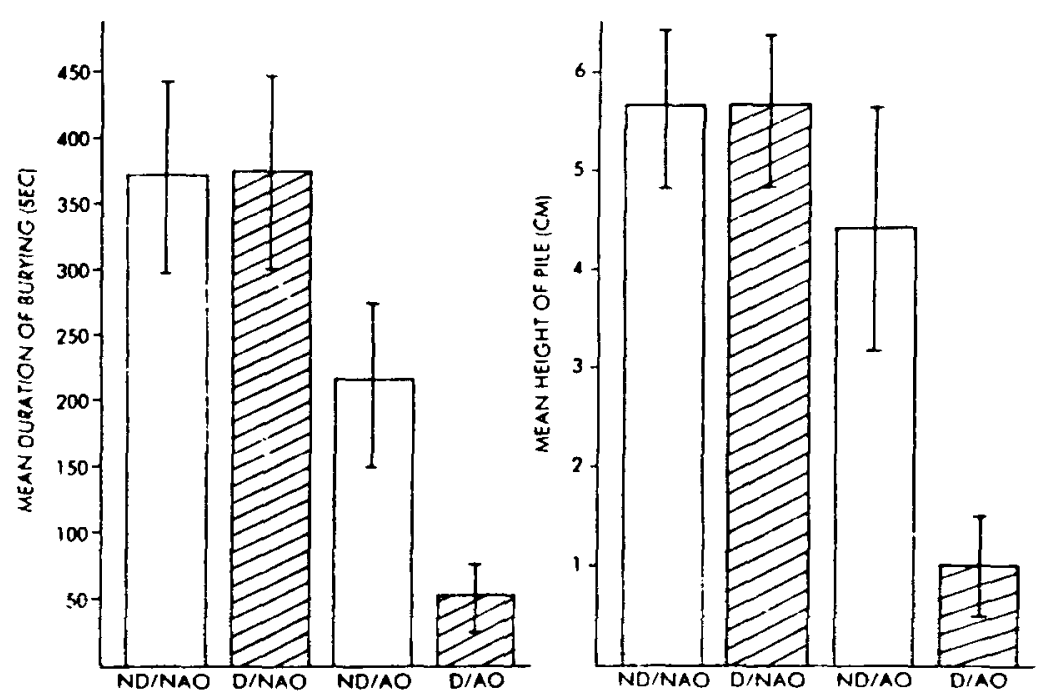

Figure 1. Mean duration of burying and heights of piles shown by defeated intruders tested in the presence of alpha odors (D/AO), nondefeated intruders tested with alpha odors (ND/AO), defeated intruders tested with nonalpha odors (D/NAO), and nondefeated intruders tested with nonalpha odors (ND/NAO). 
main effects nor the interaction of the defeat and odor manipulations were statistically significant at the .05 level, primarily because of the large within-group variability. It should be noted that these latencies were not considered to be a good measure of the subjects' fear of the test environment, prior to the prod shock, because the rats probably had not recovered from being placed in the chamber, having the camera positioned above the chamber, and hearing the experimenter leave the room. All of the rats showed erratic exploratory/flight behavior prior to time that they made their initial contact with the electrified prod.

The mean duration-of-burying results for the four colony-exposed groups are presented in Figure 1. Although the presence of alpha odors in the bedding material resulted in a reduction in the duration of defensive burying, the greatest suppression in burying occurred for the group that had been defeated by an alpha rat and was later tested with alpha odors (i.e., Group D/AO).

A two-way ANOVA of the time spent burying showed that alpha odors significantly suppressed this response $[F(1,28)=14.68, p<.01]$, whereas alpha defeat did not. Although the interaction between odors and defeat was not statistically significant, the results of plannedcomparison tests indicated that both groups tested with nonalpha odors buried more $(p<.01)$ than did Group $\mathrm{D} / \mathrm{AO}$. The difference in burying time between the defeated and the nondefeated groups tested with the alpha odors was also significant at the .01 level.

The mean height-of-pile scores for the four colonyexposed groups are also presented in Figure 1. The pattern of these scores is similar to that of the duration-ofburying scores. A two-way ANOVA indicated that alpha odors suppressed burying $[F(1,28)=11.21, p<.01]$. The effects of alpha defeat and the interaction of defeat $x$ odors were found to approach, but not reach, statistical significance, at the .05 level. The results of plannedcomparison tests indicated that both of the nonalpha-odor groups and Group ND/AO differed significantly ( $p s<$ .01) from Group D/AO.

Figure 2 illustrates the mean duration-of-feezing behavior observed for the four groups. Clearly, the group that had been previously defeated and was tested in the presence of alpha odors (i.e., Group D/AO) showed more freezing than did the other three groups. A two-way ANOVA indicated that the groups that had been previously defeated showed significantly more freezing than did the nondefeated groups $[F(1,28)=14.96, p<.01]$. This analysis also indicated that the groups that were exposed to the alpha odors during testing showed more freezing than did groups exposed to the odors of nonalpha residents $[F(1,28)=4.92, p<.05]$. More importantly, the interaction between these two main effects was found to be significant $[F(1,28)=5.77, p<.05]$, and plannedcomparison tests revealed that Group D/AO showed significantly $(p s<.01)$ more freezing than did the other three groups, which did not differ significantly from one another. Typically, the rats showed freezing in one of the two corners of the test chamber that was opposite the wall from which the prod was mounted, and none of them froze within $5 \mathrm{~cm}$ of the prod.

These findings indicate that the defensive burying paradigm was effective in demonstrating that a single session of conspecific defeat, like a series of inescapable shocks, disrupts conditioned prod burying and increases freezing, particularly when defeated rats are exposed to the odors of alpha residents during testing. It is important to note that the defeated subjects were exposed to and bitten by very aggressive alpha rats that failed to show a reduction in aggression when the intruder engaged in submissive behavior. It is very doubtful that the intruders were able to control the onset, offset, or intensity of the attacks made by the alpha residents. Thus, this type of defeat experience probably represents an example of exposure to an inescapable, or uncontrollable, stressor. However, the intruders in the present experiment had only one defeat session involving three to five bites, as opposed to 25 sessions of repeated defeat by conspecifics (Williams \& Lierle, 1988) or a session of 80 inescapable shocks (Williams, 1987). To account for the enhanced effect produced by the combination of prior defeat and alpha odors during testing, it is speculated that the alpha odors may have become conditioned stimuli when they were paired with even a few bites made by an alpha resident. Furthermore, these odors may have accentuated certain fear-mediated reactions (i.e., freezing) when they were later present in the prod-shock test situation. The results of Experiment 3, to be described later in this paper, provide strong support for the notion that ethologically relevant odors become effective conditioned stimuli after as few as five pairings with a painful stimulus.

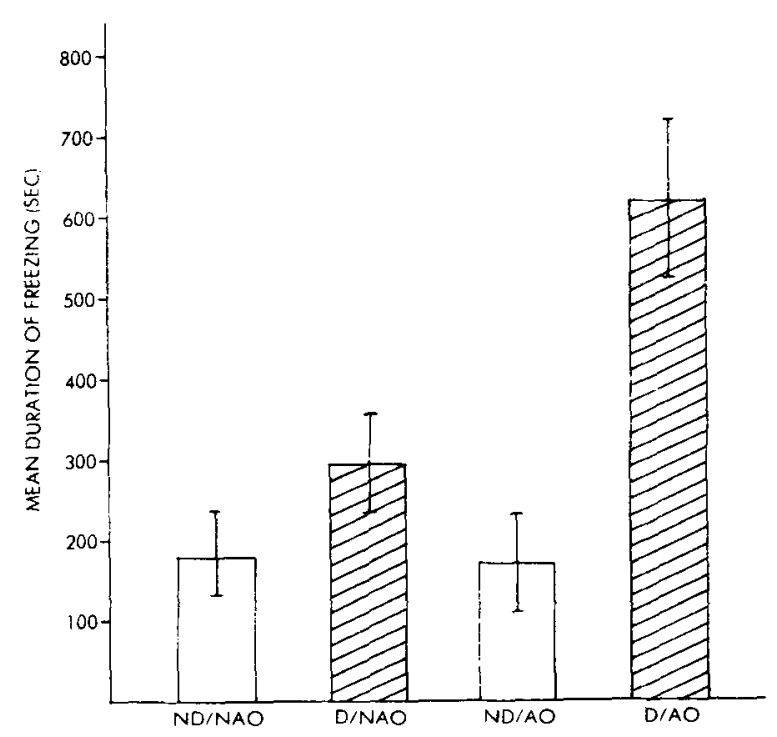

Figure 2. Mean duration of freexing shown by defeated intruders tested in the presence of alpha odors (D/AO), nondefeated intruders tested with alpha odors (ND/AO), defeated intruders tested with nonalpha odors (D/NAO), and nondefeated intruders tested with nonalpha odors (ND/NAO). 


\section{EXPERIMENT 2}

The results of Experiment 1 suggest that odors associated with conspecific defeat, as a form of social stress, induce similar fear-motivated defensive responses as odors associated with uncontrollable shock (e.g., Williams, 1987). The question remains as to whether conditioned cues from other types of ethological stressors, such as predatory stressors, would produce similar alterations in defensive responses. Several investigators have reported that rats show pronounced defensive reactions to a cat, even when they have not had previous experience with a cat (e.g., Blanchard \& Blanchard, 1971; Blanchard, Fukunaga, \& Blanchard, 1976; Lester \& Fanselow, 1985). On the basis of the SCFD theory, inescapable exposure to a cat should produce fear-mediated changes in later defensive responses for rats when they are reexposed to cat odors during testing. Furthermore, according to this theory, the alterations in defensive behavior produced by cat exposure and later cat odors should be similar to those previously reported for stress odors associated with inescapable shock and alpha defeat. That is, exposure to a cat should result in a suppression in prod burying and an increase in freezing, particularly during burying tests with cat odors present. On the other hand, it could also be argued that noncontact exposure to a cat, without the experience of pain, may be sufficiently different from being shocked via tail electrodes or bitten by an alpha conspecific that the resulting changes in defensive behavior would be quite different.

This experiment involved a similar factorial design as that used in Experiment 1, with separate groups either ex- posed or not exposed to a cat as a stressor and later tested for defensive prod burying and freezing in the presence or absence of cat odors. It was hypothesized that cat odors would induce a moderate level of fear that would decrease prod burying and increase freezing to some degree. More substantial aberrations in behavior were expected to occur for rats that had been previously exposed to a cat and were later tested with cat odors. However, the precise degree to which these response changes would parallel those produced by inescapable shock and conspecific defeat remained an empirical question.

\section{Method}

Subjects. Thirty-two male albino rats of Holtzman descent, weighing $500-560 \mathrm{~g}$ at the start of the experiment, were used as subjects; 5 cats were used as predatory stressors.

Apparatus. The cats were kept in a $3.5 \times 4.0 \mathrm{~m}$ room in which they were free to roam. A hole was cut into the door of the room so that the cats could be observed. During the predatory-exposure session, one of the 5 cats was placed in a $70 \times 40 \times 70 \mathrm{~cm}$ polypropylene traveling cage with wide-gauge mesh doors made of the same material. The rats were placed in a wire-cloth exposure cage $(45 \times 30 \times 30 \mathrm{~cm})$ that consisted of two double-size rack cages, which were clamped together. The four defensive burying test chambers, the shock source, and the video equipment were the same as those used in Experiment 1.

Procedure. All 32 rats were habituated to the test chamber for 4 consecutive days using the same procedure that was described in Experiment 1. On Day 5, the rats were randomly assigned to either a cat-exposure or a confinement-control condition that did not involve the presence of a cat. Rats assigned to the cat-exposure group were placed inside an exposure cage that was positioned directly in front of a larger carrying cage containing a randomly selected cat. The wire-cloth wall of the subject's cage and the large openings in the mesh door of the cat's cage allowed for visual, au-
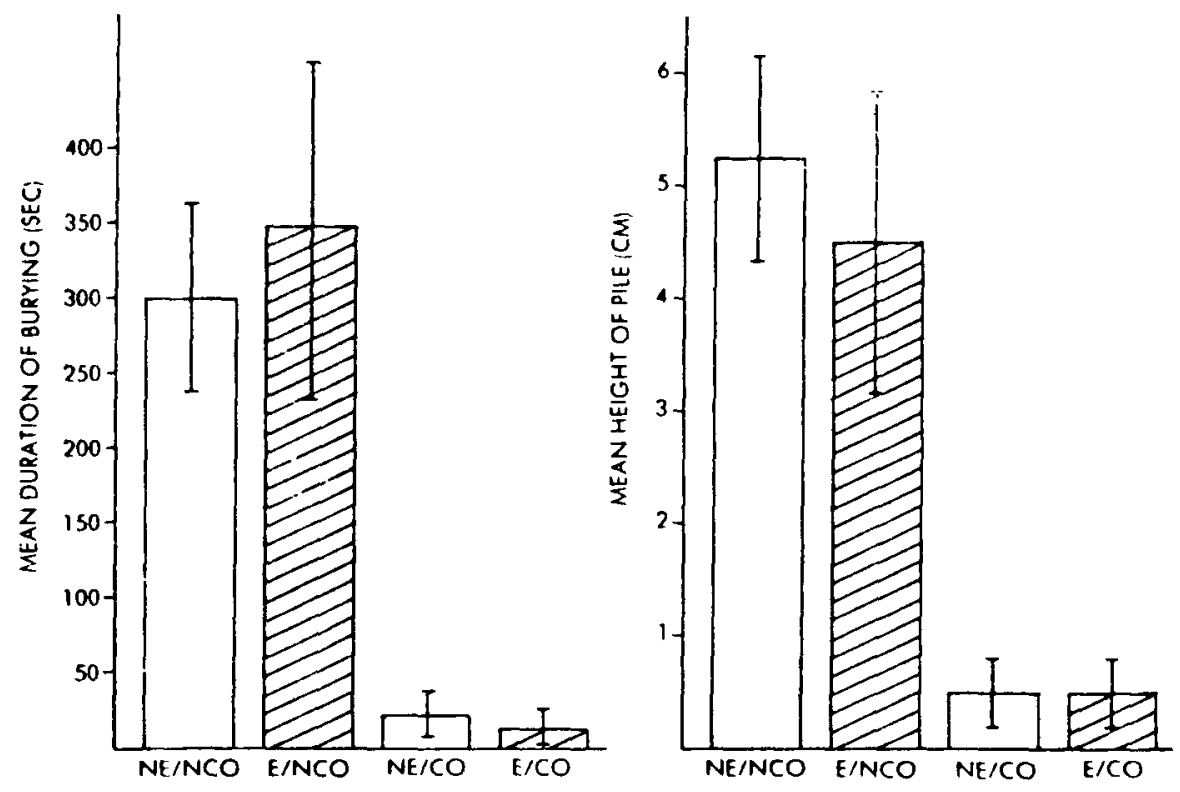

Figure 3. Mean duration of burying and heights of piles shown by groups of subjects exposed to a cat and later tested in the presence of cat odors $(E / C O)$, not exposed to a cat and tested with cat odors (NE/CO), exposed to a cat and tested with no cat odors (E/NCO), and not exposed to a cat and tested with no cat odors (NE/NCO). 
ditory, and olfactory transmission of stimuli, but physical contact was impossible. In the control condition, the rats were placed inside a wire-cloth cage that was positioned directly in front of an empty cat-carrying cage. The behavior of the rats and cats was monitored via a video camera, located in an adjacent room and directed at the subjects through a hole in the door. Each of these exposure/confinement sessions lasted $45 \mathrm{~min}$, and 2 -min recordings were made every $15 \mathrm{~min}$.

On Day 6, the subjects were individually placed in their preassigned test chambers either with or without the presence of cat odors. During prod-shock testing for the cat-odor groups, samples of feces, urine, and hair from the soiled litter boxes of the cats were used as contextual-odor cues. Shortly after being placed in the test chambers, the rats were each given a brief prod shock and their behavior was observed over the following $18 \mathrm{~min}$. The durations of burying and freezing and the heights of the piles were recorded using the procedures described in Experiment 1 . The subjects were scheduled so that no more than 8 rats were actually tested on a single day. Thus, a factorial design was created consisting of the following four groups of subjects: exposure to a cat and tested with cat odors (E/CO), exposure to a cat and tested with no cat odors (E/NCO), no exposure to a cat and tested with cat odors $(\mathrm{NE} / \mathrm{CO})$, and no exposure to a cat and tested with no cat odors (NE/NCO).

\section{Results and Discussion}

The mean duration-of-burying scores for the four groups are shown in Figure 3. Rats that were exposed to cat odors during testing clearly buried less than those that were not exposed to such odors. A two-way ANOVA indicated that the presence of cat odors during testing caused a significant decrease in burying time $[F(1,28)=23.40$, $p<.01$ ]. Prior exposure to a cat had no significant effect on later burying, and there was no interaction between cat exposure and odors. A Newman-Keuls post hoc test indicated that both of the groups tested in the presence of cat odors differed significantly $(p s<.01)$ from each of the groups that were not tested with cat odors.

The mean height-of-pile scores for the four groups are also presented in Figure 3. A two-way ANOVA indicated that cat odors caused a significant decrease in the heights of piles $[F(1,28)=32.68, p<.01]$. As was the case for the time spent burying, previous exposure to a cat had virtually no effect on the heights of piles, and there was no significant interaction between cat exposure and test odors. A Newman-Keuls post hoc test revealed that both of the groups tested in the presence of cat odors differed significantly $(p s<.01)$ from each of the groups that were tested with no cat odors.

The mean freezing scores for the four groups are presented in Figure 4. It is apparent that none of the groups showed very much freezing behavior. A two-way ANOVA indicated that neither cat odors nor exposure to cats had a significant effect on duration of freezing and there was no interaction effect between cat exposure and test odors. A Newman-Keuls post hoc test indicated that none of the four groups differed at the .05 level.

Consistent with previous findings (e.g., Blanchard \& Blanchard, 1971), freezing was found to be the dominant defensive response when the rats were actually exposed to a cat during the stress session of this experiment. However, the prod-shock testing data from this study clearly indicate that the presence of cat odors completely suppressed burying behavior, but failed to induce freezing, regardless of whether or not the rats had been previously exposed to a cat. Visual observation of the rats tested in the presence of cat odors indicated that they all showed a strong startle/withdrawal reaction as an unconditioned response to the prod shock. Thus, the lack of freezing in response to cat odors during testing cannot be easily attributed to an analgesic reaction that may have prevented the prod or the odors from becoming a conditioned source of fear. Furthermore, it is difficult to conceive that an analgesic reaction prevented conditioning because of the high intensity (i.e., $6.5 \mathrm{~mA}$ ) of the shock delivered via the prod. Previous experiments in our laboratory have shown that a shock intensity as low as $3.0 \mathrm{~mA}$ can reliably elicit significant amounts of defensive prod burying during tests with no stress odors. As opposed to freezing, all of the subjects that were tested with cat odors sniffed at the soiled bedding and slowly explored the entire test chamber with a crouched, stretched posture. This type of behavior, which has been recently referred to as "risk-assessment", responding to cat odors by Blanchard, Blanchard, and Hori (1989), was rarely observed for rats tested with no cat odors in the present experiment. Therefore, regardless of whether or not the rats had prior exposure to a cat, testing with cat odors elicited a pattern of responses that was clearly different from that previously noted with odors from shocked conspecifics or from alpha males.

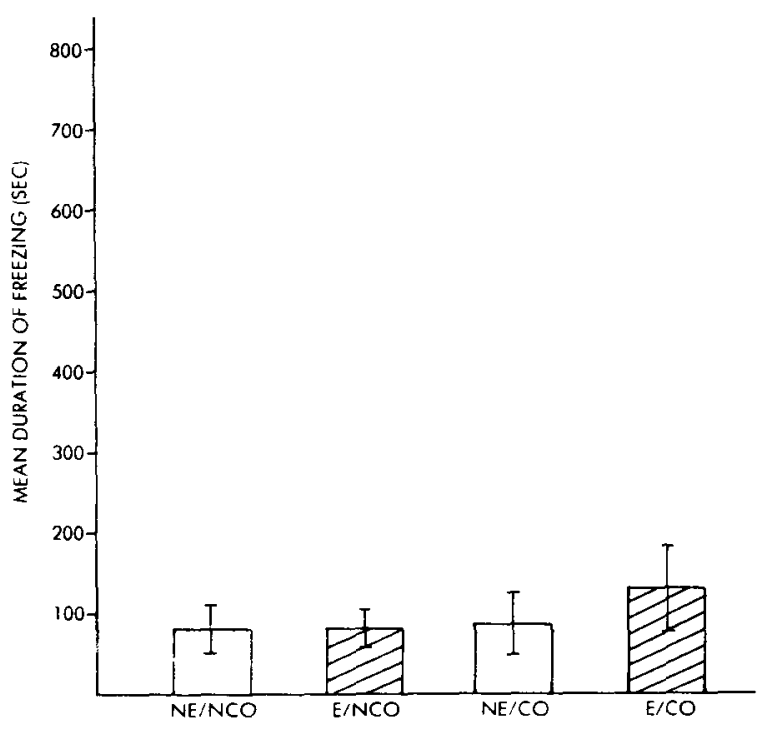

Figure 4. Mean duration of freezing shown by groups of subjects exposed to a cat and later tested in the presence of cat odors $(\mathrm{E} / \mathrm{CO})$, not exposed to a cat and tested with cat odors (NE/CO), exposed to a cat and tested with no cat odors (E/NCO), and not exposed to a cat and tested with no cat odors (NE/NCO). 


\section{EXPERIMENT 3}

The results of the previous two experiments raise some interesting issues. Perhaps the high degree of freezing in Experiment 1 was due to the fact that alpha odors were associated with the pain from being bitten several times during defeat as well as with the fear of an attacking conspecific. On the other hand, the lack of freezing in Experiment 2 may have been due to the fact that the rats were protected from physical harm by the wire cages during their exposure to a cat. Thus, the cat odors used during subsequent testing were associated with a fearful, but not a painful, experience. This suggests that the specific behavioral effects of ethologically relevant odors may be a function of whether or not they have been associated with pain. Therefore, one of the purposes of Experiment 3 was to examine the role that pain versus fear plays in producing subsequent stress-induced changes in burying and freezing during prod-shock testing. On the basis of the findings of Experiment 2, it was believed that cat odors alone would be sufficient to disrupt the defensive burying response. Furthermore, it was hypothesized that prior exposure to shock would be necessary to induce freezing and that freezing would only occur if cat odors were also present during later prod-shock testing.

The findings of the previous experiments also raise a question as to whether cat odors, as putative unconditioned stimuli, might be easier to associate with a painful unconditioned stimulus than an odor that is hedonically neutral. Perhaps rats have evolved specialized perceptual and learning systems that prepare the species to associate a potentially fear-relevant, conditioned stimulus (CS) with a painful unconditioned stimulus (US). Thus, Experiment 3 was also designed to examine the relative ease with which cat odors, as compared with the hedonically neutral odor of citronella (Lester \& Fanselow, 1985), would influence conditioned prod-burying and freezing responses following various numbers of trials with inescapable preshock. Specifically, it was hypothesized that the odor of citronella, without prior shock, would be sufficiently novel to slightly disrupt burying but not to induce freezing. On the other hand, it was predicted that citronella would clearly suppress burying and induce freezing during subsequent testing if a sufficient number of preshock trials were given. Finally, cat odors were expected to suppress burying and induce freezing significantly more than the odor of citronella when even a few preshock trials were paired with each of these potential CS odors.

\section{Method}

Subjects. Seventy-two male albino rats of Holtzman descent, weighing between 460 and $520 \mathrm{~g}$, were used as subjects in this experiment. All rats were housed singly prior to the experiment and had food and water continuously available in their home cages.

Apparatus. All subjects were given preshocks in a $45 \times 20 \times$ $20 \mathrm{~cm}$ BRS/LVE shuttlebox with the barrier wall removed. Scrambled grid shocks were delivered from a Lafayette 82400 shock source. The four defensive burying chambers, the white-noise gener- ator, and the video equipment were the same as those used in Experiment 1 .

Procedure. All of the rats were initially habituated to the test chamber using the same 4-day procedure that was described in Experiment 1. On Day 5, 8 rats were randomly assigned to one of nine groups that were to be tested with different odors. There were three cat-odor (CO) groups, three citronella-odor (CI) groups, and three no-odor (NO) control groups. Each of the three test-odor groups was given a preshock session with 1 (PS1), 5 (PS5), or 30 (PS30) shocks. These preshocks were given to the rats in the shuttlebox apparatus, and each shock trial consisted of a 3-sec, 1-mA presentation of scrambled grid shock given at random intervals, ranging between 45 and $70 \mathrm{sec}$. The $C O$ groups were given preshocks in the presence of cat odors that consisted of samples of soiled litter and cat hair obtained from the litter boxes. The CI groups were given preshocks in the presence of shavings from a candle made with citronella oils. It was also decided that cat odors should be present during the preshock-conditioning sessions for the NO test groups in order to control for possible analgesic reactions that might be elicited by the cat odors as contextual stimuli (Lester \& Fanselow, 1985). After each preshock treatment, the shuttlebox was thoroughly cleaned with a damp sponge and an ammonia-based cleanser and then dried.

Twenty-four hours later, each subject was placed in a defensive burying chamber with the previously assigned cat, citronella, or no specific odors added to the familiar bedding of the chamber. Upon contact with the prod, the rats were manually given a 6.5mA shock, which was terminated when the rat withdrew its forepaw. They were then observed for a period of $18 \mathrm{~min}$, and their cumulative burying and freezing times were recorded, using the procedures described in Experiment 1. If the rat buried the prod, the height of the highest pile within $5 \mathrm{~cm}$ of the vicinity of the prod was measured and recorded. After each test, the bedding was discarded and replaced. Testing of the subjects was scheduled so that no more than 4 rats were observed on a single day.

\section{Results and Discussion}

The mean duration-of-burying results for the nine groups are presented in Figure 5 . It is apparent that the presence of cat odors, as well as citronella, suppressed the amount of defensive prod burying. A two-way ANOVA followed by Newman-Keuls post hoc comparisons indicated that citronella and cat odors significantly suppressed burying $[F(2,63)=17.60, p<.01]$, whereas the number of preshock trials and the interaction between test odors and the number of preshocks were not found to be significant at the .05 level. Planned-comparison tests revealed that rats conditioned with cat odors for one preshock trial (i.e., Group CO/PS1) buried significantly less $(p<.01)$ than did rats previously conditioned with citronella for one trial (i.e., CI/PS1). Both of these groups, in turn, buried significantly less $(p<.01)$ than did the no-odor rats given one preshock with cat odors when in the shuttlebox (i.e., Group NO/PS1). Plannedcomparison tests for groups given 5 and 30 preshocks indicated that the $\mathrm{CI}$ groups did not differ significantly from the $\mathrm{CO}$ groups, whereas these odor groups showed significantly less $(p<.001)$ burying than did the NO groups that were previously given either 5 or 30 trials of shock. Since the height-of-pile scores for each group were significantly correlated with the duration-of-burying scores, 


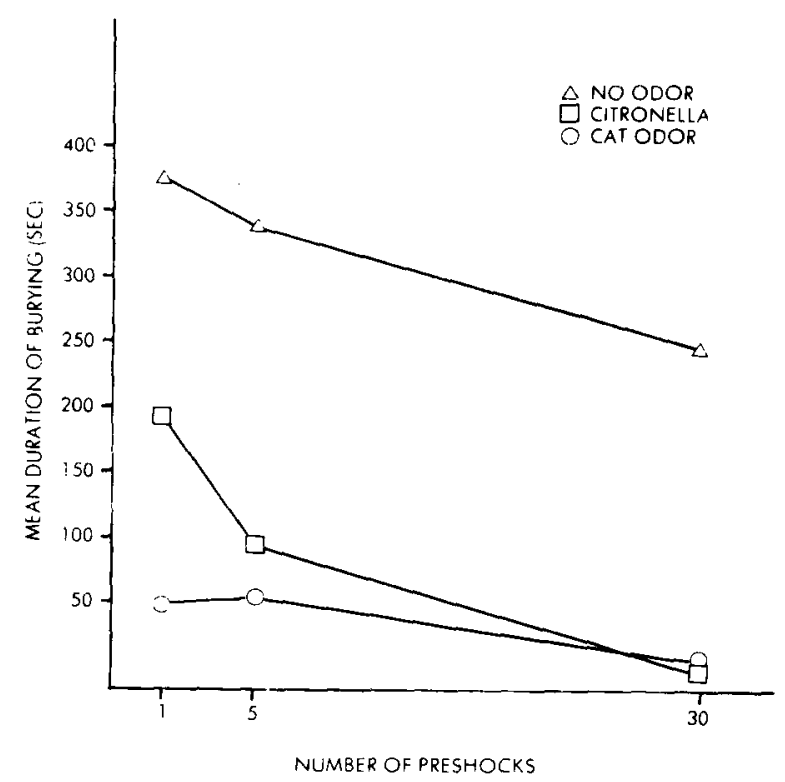

Figure 5. Mean duration of burying shown by groups of subjects tested in the presence of no distinctive odor (NO), citronella odor (C), or cat odors (CO) after having been given 1, 5, or 30 trials of preshock.

the pattern of significant results that was observed virtually replicated the previously mentioned findings.

Figure 6 presents the mean duration-of-freezing scores observed for the nine groups. A two-way ANOVA indicated that the number of preshocks significantly influenced the duration of freezing during tests of defensive burying $[F(2,63)=50.83, p<.01]$, as did the various test odors $[\mathrm{F}(2,63)=33.91, p<.01]$. There was also a significant interaction between the number of preshocks and test odors $[F(4,63)=16.23, p<.01]$. Planned-comparison tests revealed that Group CO/PS5 froze significantly more than Group CO/PS1 $(p<.01)$, and Group CI/PS5 showed significantly more freezing than did Group CI/PS1 $(p<.01)$. More importantly, however, Group CO/PS5 spent significantly more time freezing than did Group CI/PS5 $(p<.01)$. For groups that were given 30 preshock trials, the two odor conditions resulted in significantly more freezing than did the no-odor condition $(p<.001)$.

The results of Experiment 2 clearly showed that cat odors produced risk-assessment exploratory behavior in rats, rather than freezing, regardless of whether or not the rats had had prior noncontact exposure to a cat. In contrast, the findings of the present experiment indicate that cat odors induce a high level of freezing during tests of defensive burying if the odors have been previously paired with shock. This suggests that it is necessary for the odor of a predator to be associated with a painful experience in order for it to elicit subsequent freezing in rats. The results of this experiment also show that cat odors produced significantly more freezing than did the odor of citronella after each of these odors was paired with only five preshocks. Conditioned cat odors were also found to suppress defensive burying to a significantly greater degree than did the odor of citronella for groups that had been given only a single trial of preshock in the presence of each of these odors. This finding not only confirms that cat odors were more effective conditioned stimuli, but it also suggests that disruptions in defensive burying may be a more sensitive index of fear than the occurrence of freezing behavior.

\section{GENERAL DISCUSSION}

The results of Experiment 1 were very similar to those of the defensive burying study reported by Williams (1987), using inescapable shock as a stressor. However, defeat by an alpha conspecific, per se, did not disrupt later burying or increase freezing as much as did inescapable shock. The greater potency of shock may have been due to the fact that the preshock session in Williams' previous study involved 80 shock trials, whereas Experiment 1 involved a single session of defeat with only 3-5 bites on the intruder's back. Despite their differences in potency, these stressors were both very effective in terms of augmenting decrements in burying and increments in freezing when rats were tested in the context of conspecific stress and alpha odors, respectively.

Although the unconditioned responses observed during actual exposure to inescapable shock (Williams, 1987) and the defeat encounters in Experiment 1 were very different, the odor cues that were associated with these two stressors produced very similar changes in terms of burying and freezing behaviors. According to the SCFD the-

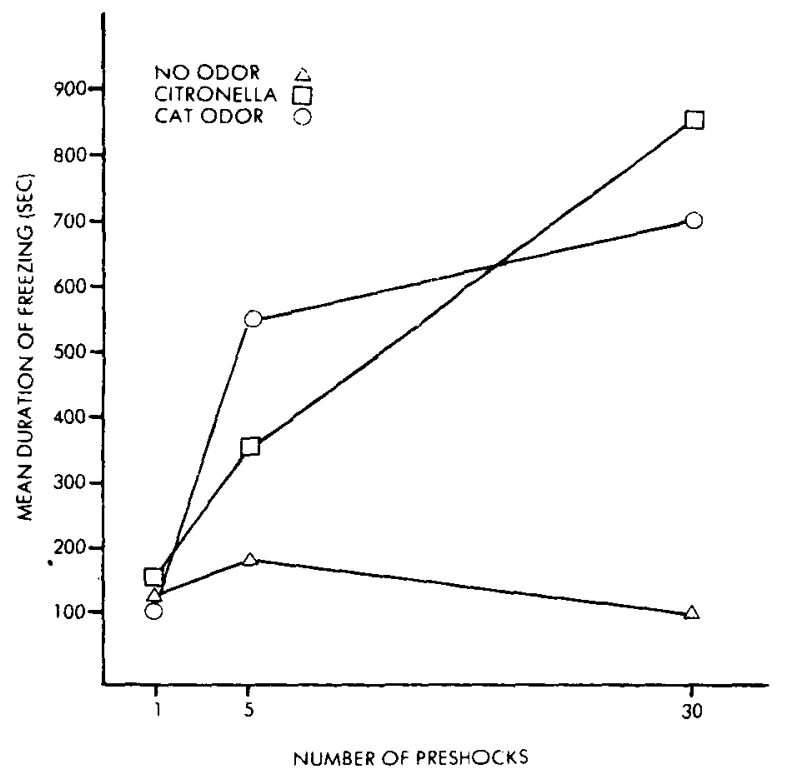

Figure 6. Mean duration of freezing shown by groups of subjects tested in the presence of no distinctive odor (NO), citronella odor (CI), or cat odors (CO) after having been given 1, 5, or 30 trials of preshock. 
ory (Williams, 1989), organisms become conditioned to fear the contextual odors associated with inescapable shock and defeat situations, and these odors are predicted to induce alterations in subsequent behavior. Previous studies that have examined learned-helplessness effects have not involved ethological stressors and responses. Rather, researchers in this area have implicitly assumed that the use of inescapable shock can be generalized to a wide variety of natural stressors and behaviors (e.g., Maier \& Seligman, 1976). The results of Experiment 1, and those previously reported by Williams and Lierle (1988), show that the combination of conspecific defeat and the presence of fear odors during testing causes changes in subsequent species-typical behaviors that parallel those produced by inescapable shock.

Consistent with the SCFD theory (Williams, 1987, 1989), it is further assumed that freezing is likely to be the most prevalent defensive response to occur in the prod-shock situation in Experiment 1 because of the stimulus control exerted by the diffuse presence of stress odors as support stimuli (Tolman, 1932). Thus, freezing is predicted to occur during prod-shock testing because of the ubiquitous nature of the feared odors throughout the test chamber. This explanation is by no means an extension of the concept of a hierarchy of species-specific defense reactions (SSDRs). According to Bolles (1970), SSDRs are hierarchically ordered in terms of their success in allowing the organism to escape from a threatening situation. Thus, freezing would be predicted to occur in the defensive burying paradigm because it is successful in preventing the rat from repeated exposures to the prod shock. However, this interpretation is not able to account for why the rats in the present research showed more burying in the nonstress-odor context, whereas they engaged in more freezing in the stress-odor context. In contrast, the SCFD theory predicts that the defensive behaviors of freezing and burying are a function of the organism's past history and the nonlocalized nature of the contextual fear odors in the test environment (Williams, 1989).

Exposure to cats in Experiment 2, unlike inescapable shock or defeat as a stressor, had no apparent effect on the rats' subsequent responses to the putative conditioned odors of cats as contextual cues in the defensive burying chamber. Perhaps prior exposure to a cat failed to decrease the amount of burying during testing because of a "floor effect." That is, since the presence of cat odors reduced defensive burying to a level that was close to zero, further reductions in burying may not have been possible to assess. However, the question still remains as to why noncontact cat exposure and later testing with cat odors did not elicit freezing behavior. As mentioned, cat odors, regardless of prior cat exposure, were found to consistently elicit an alternative defensive behavior that involved exploration of the entire chamber with a stretched posture and continual sniffing. Blanchard, Blanchard, and Hori (1989) have also reported the occurrence of this type of risk-assessment behavior when rats are exposed to cat odors on the ground surface of colony cages in which the rats can make complex burrow systems. Although brief episodes of approaching and investigating the prod occurred prior to prod burying by the rats in the no-odor groups, risk-assessment exploration of the bedding material occurred throughout the entire test period for the rats that were given prod shock and then tested in the presence of cat odors.

The results of Experiment 2 and Group CO/PS1 of Experiment 3 showed that a complete suppression of prod burying can occur without very much freezing behavior. This suggests that the previously reported suppressions of burying during tests with conspecific stress odors (Williams, 1987) and alpha odors (Experiment 1) were not caused by the occurrence of freezing as an incompatible, competing response. Nevertheless, the suppression of burying with cat odors in Experiment 2 could be accounted for on the basis of competing defensive behaviors because risk-assessment exploration may have been incompatible with both burying and freezing. However, it should also be noted that the results of Experiment 3 indicate that freezing takes precedence over risk-assessment behavior when cat odors are paired with shock for five or more trials. Regardless of whether suppressions in burying are a result of stimulus-control or responsecompetition processes, these findings clearly demonstrate that different types of ethological stressors, in conjunction with their innately associated odors, produce very different patterns of defensive responses.

A third explanation of the suppression of prod burying in the presence of conspecific and predatory odors is that fear induces an endogenous analgesic process that reduces the pain of the prod shock to the point that it fails to produce conditioning and/or activate burying behavior. Odors of stressed conspecifics (Fanselow, 1985), the presence of a cat (Lester \& Fanselow, 1985), and cues associated with uncontrollable shock (Maier et al., 1983) have all been shown to activate opioid analgesia in rats. However, it is difficult to imagine that this type of stressinduced analgesia would be powerful enough to mitigate the conditioning and/or burying produced by the use of a 6.5-mA prod shock. Furthermore, the freezing observed during tests with conspecific stress odors (Williams, 1987) and alpha odors (Experiment 1) typically occurred in the corners of the test chamber that were opposite the wall on which the prod was mounted. Contrary to an analgesia interpretation, this finding suggests that the prod was a conditioned, localized source of fear during tests of burying with the stress and alpha odors. However, an analgesic explanation of the suppression of burying cannot be evaluated in terms of the results observed in Experiment 2 , because the rats rarely showed freezing in response to cat odors and their risk-assessment exploratory behavior occasionally involved investigation of the shock prod.

A fourth explanation for the suppression of burying behavior is that the presence of fear odors may have blocked or overshadowed the prod from becoming associated with 
the shock. However, this explanation is also inconsistent with the fact that the rats did not freeze in the vicinity of the prod when they were tested with conspecific stress or alpha odors. Finally, it could also be argued that the disruption in burying occurred because the alpha or cat odors, during testing as opposed to conditioning, determined what specific defensive behavior would be performed.

Conspecific defeat and later testing with alpha odors increased freezing in Experiment 1, whereas cat odors failed to produce freezing in Experiment 2. A possible reason for this discrepancy is that the alpha odors were associated with both fear and pain during conspecific attacks, whereas the cat odors were associated with fear, but not with pain, when the rats were exposed to a cat while they were in a protective cage. The odor-shock conditioning results of Experiment 3 also imply that fear and pain lead to different types of defensive behavior. As mentioned, cat odors had to be explicitly associated with five trials of nociceptive stimulation (i.e., electric shock) before they produced freezing. Although it could be argued that the predatory-exposure procedure used in Experiment 2 may not have been sufficiently fear-inducing, we currently contend that painful stimulation must be associated with an ethologically relevant odor in order for freezing to be the predominant defensive response.

Since the alpha odors in Experiment 1 were found to accentuate changes in the defensive responses of colony intruders that had been bitten only a few times, it appears that certain ethological stimuli can be easily associated with nociceptive events. Stronger support for this argument is found in terms of the results of Experiment 3, in which the rats were conditioned more effectively, and with fewer trials, by pairing shock with cat odors, as opposed to the hedonically neutral odor of citronella. These findings appear to support the research and theorizing of a number of investigators (e.g., Mineka \& Cook, 1987; Ohman, Fredrikson, Hugdahl, \& Rimmo, 1976; Seligman, 1970, 1971), who claim that organisms may show selectivity, or biological preparedness, in terms of learning to associate certain CSs with particular types of USs. For example, Mineka and Cook reported that monkeys can easily acquire a strong fear reaction to pictures of snakes, but they could not be conditioned to fear pictures of flowers. However, LoLordo and Droungas (1989) have recently claimed that the validity of the concept of selective associations in human fear has not been adequately tested because few studies have compared the conditioning (or extinction) of separate groups that have different types of CSs paired with aversive and appetitive USs. This criticism is also applicable to our findings since the cat odors, relative to the odor of citronella, may have been more salient, and therefore a more effective CS, regardless of what sort of US was used.

In conclusion, the findings of this research demonstrate the importance of examining the influence of ethological stressors, and their related odors, on a variety of defensive responses. Such research allows for the direct ex- amination of the ability of various learning theories and interpretations (e.g., the SCFD theory, learnedhelplessness theory, competing-response interpretations) to predict and explain an organism's behavior in its natural environment. For instance, the results of the present research suggest that ethological stressors may need to involve pain, or perhaps an extremely high level of fear, in order for their associated odors to have subsequent effects on certain defensive behaviors (e.g., freezing). Finally, studies using ethological stressors, and their related odors, may also enable us to learn more about specialized defensive responses (e.g., risk-assessment exploration) that organisms have evolved in order to cope with specific types of danger.

\section{REFERENCES}

Blanchard, R. J., \& Blanchard, D. C. (1971). Defensive reactions in the albino rat. Learning \& Motivation, 2, 351-362.

Blanchard, R. J., \& BlancharD, D. C. (1987). An ethoexperimental approach to the study of fear. Psychological Record, 37, 305-316.

Blanchard, R. J., Blanchard, D. C., \& HoRI, K. (1989). An ethoexperimental approach to the study of defense. In R. J. Blanchard, P. F. Brain, D. C. Blanchard, \& S. Parmigiani (Eds.), Ethoexperimental approaches to the study of behavior (pp. 114-136). Dordrecht, The Netherlands: Martinus Nijhoff.

Blanchard, R. J., Fukunaga, K. K., Blanchard, D. C. (1976). Environmental control of defensive reactions to a cat. Bulletin of the Psychonomic Society, 8, 179-181

Bolles, R. C. (1970). Species-specific defense reactions and avoidance learning. Psychological Review, 77, 32-48.

Bolles, R. C., \& Fanselow, M. S. (1980). A perceptual-defensiverecuperative model of fear and pain. Behavioral \& Brain Sciences, 3, 291-323

FANSELOW, M. S. (1985). Odors released by stressed rats produce opioid analgesia in unstressed rats. Behavioral Neuroscience, 99, 589-592.

FANSElow, M. S., Lester, L. S. (1987). A functional behavioristic approach to aversively motivated behavior: Predatory imminence as a determinant of the topography of defensive behavior. In R. C. Bolles \& M. D. Beecher (Eds.), Evolution and learning (pp. 185-212). Hillsdale, NJ: Erlbaum.

Fanselow, M. S., Sigmundt, R. A., \& Williams, J. L. (1987). Response selection and hierarchical organization of species-specific defensive reactions: The relationship between freezing, flight, and defensive burying. Psychological Record, 37, 381-386.

Gray, D. S., Terlecki, L. J., Treit, D., \& Pinel, J. P. J. (1981). Effect of septal lesions on conditioned defensive burying. Physiology \& Behavior, 27, 1051-1056.

LESTER, L. S., \& FANSELOW, M. S. (1985). Exposure to a cat produces opioid analgesia in rats. Behavioral Neuroscience, 4, 756-759.

LoLordo, V. M., \& Droungas, A. (1989). Selective associations and adaptive specializations: Taste aversions and phobias. In S. B. Klein \& R. Mowrer (Eds.), Contemporary learning theory: Instrumental conditioning and the impact of biological constraints on learning (pp. 149-180). Hillsdale, NJ: Erlbaum.

Maier, S. F., Drugan, R., Grau, J. W., Hyson, R., Maclennan, A. J., Moye, T., Madden, J., a Barchas, J. D. (1983). Learned helplessness, pain inhibition and the endogenous opiates. In M. D. Zeiler \& P. Harzem (Eds.), Advances in animal behavior (Vol. 3, pp. 275-323). New York: Wiley.

MaIER, S. F., SEligmaN, M. E. P. (1976). Learned helplessness: Theory and evidence. Joumal of Experimental Psychology: General, 105, 3-46.

MineKa, S., \& CoOK, M. (1987). Social learning and the acquisition of snake fear in monkeys. In T. Zentall \& G. Galef (Eds.), Comparative social learning (pp. 51-73). New York: Erlbaum.

Ohman, A., Fredrikson, M., Hugdahl, K., Rimmo, P. A. (1976). The premise of equipotentiality in human classical conditioning: Con- 
ditioned electrodermal responses to potentially phobic stimuli. Journal of Experimental Psychology: General, 105, 313-337.

PeAcock, E. L., \&ong, P. T. P. (1982). Defensive burying in the rat: A behavioral field analysis. Animal Learning \& Behavior, 10, 103-107.

Pinel, J. P. J., \& Treit, D. (1978). Burying as a defensive response in rats. Journal of Comparative Physiological Psychology, 92, 708-712.

Pinel, J. P. J., \& Treit, D. (1981). The conditioned defensive burying paradigm and behavioral neuroscience. In T. E. Robinson (Ed.), Behavioral contributions to brain research (pp. 212-234). Oxford: Oxford University Press.

Seligman, M. E. P. (1970). On the generality of the laws of learning. Psychological Review, 77, 406-418.

Seligman, M. E. P. (1971). Phobias and preparedness. Behavior Therapy, 2, 307-320.

Tolman, E. C. (1932). Purposive behavior in animals and men. New York: Appleton.

Treit, D. (1985). Animal models for the study of anti-anxiety agents: A review. Neuroscience Biobehavior Review, 9, 203-222.

Williams, J. L. (1982). Influence of shock controllability by dominant rats on subsequent attack and defensive behaviors toward colony intruders. Animal Learning \& Behavior, 10, 305-313.
WILLisms, J. L. (1984). Influence of postpartum shock controllability on subsequent maternal behavior in rats. Animal Leaming \& Behavior, 12, 209-216.

Williams, J. L. (1987). Influence of conspecific stress odors and shock controllability on conditioned defensive burying. Animal Learning \& Behavior, 15, 333-341.

Williams, J. L. (1989). Ethoexperimental analysis of stress, contextual odors, and defensive behaviors. In R. J. Blanchard, P. F. Brain, D. C. Blanchard, \& S. Parmigiani (Eds.), Ethoexperimental approaches to the study of behavior (pp. 214-228). Dordrecht. The Netherlands: Martinus Nijhoff.

Williams, J. L., \& LiERLE, D. M. (1986). Effects of stress controllability, immunization, and therapy on the subsequent defeat of colony intruders. Animal Learning \& Behavior, 14, 305-314.

Williams, J. L., \& LierLe, D. M. (1988). Effects of repeated defeat by a dominant conspecific on subsequent pain sensitivity, open-field activity, and escape learning. Animal Learning \& Behavior, 16, 477-485.

(Manuscript received September 30, 1988; revision accepted for publication April 20, 1989.) 